\title{
Risk Disparity among Conglomerates and Single Entities in the Dhaka Stock Exchange
}

\author{
Selim Akhter ${ }^{1}$, Rashed Kabir $^{2}$ \& Ahasan H Sarkar ${ }^{3}$ \\ ${ }^{1}$ School of Business, University of Western Sydney, Australia \\ ${ }^{2}$ Department of Finance and Banking, University of Rajshahi, Bangladesh \\ ${ }^{3}$ Master of Commerce Candidate, University of Sydney, Australia \\ Correspondence: Selim Akhter, School of Business, University of Western Sydney, Australia. Tel: 61-02 \\ -4620-3210. E-mail: s.akhter@uws.edu.au
}

Received: August 7, 2012 Accepted: November 29, 2012 Online Published: December 22, 2012

doi:10.5539/ijbm.v8n2p50 URL: http://dx.doi.org/10.5539/ijbm.v8n2p50

\begin{abstract}
This paper gathers evidence that market risk varies considerably among companies traded in the Dhaka Stock Exchange. We find evidence of statistically significant difference in VaR between bias and random portfolios where a bias portfolio is one that comprise at least two of the five companies in a portfolio from large business groups while a random portfolio consist of any five companies picked randomly from a given sample. This renders a lesson for investors in the market, especially who are myopic in nature, that stocks with good fundamentals are better not only as long term investments but also for gains in the short-run.
\end{abstract}

Keywords: conglomerates, cholesky decomposition, stochastic simulation, value at risk (VaR)

\section{Introduction}

This paper compares risk of conglomerates and single entities listed with one of the world's most volatile stock market namely Dhaka Stock Exchange - the principal browse of Bangladesh. Using a popular risk measure called Value at risk (VaR), we investigate whether investors in DSE can minimize risk by making a bias portfolio rather than allocating funds randomly to any stock.

Developing stock markets are prone to many maladies. But the magnitude of problems and the degree of complexities are severe in countries like Bangladesh where unemployment rate is high and the legal system is weak due to vulnerable democratic political institutions. A large population of retail traders (we call them petty-players) in the market is young university graduates. Being frustrated to find a place in the job market, they gather in the stock market to try their luck. The fortune favors sometimes. They delight in success and distribute 'rosogolla' (popular dessert) as the market goes up and up without any logic. Whilst eminent economists of the country including the governor of the country's central bank smell suspicious behind the scene activities (Note 1), the finance ministry makes statements in the media immediately saying all credit for swelling of the market goes to the government or the prime-minister in particular. So does the DSE management, offending economists' suspicion as baseless. This on the one hand fuels the petty-players' greed and welcomes on the other hand the big-players (e.g. owners of garment factory, banks other businesses) to pull the market further up and quit few days later fooling the petty-players.

Bangladesh's stock market can be characterized by many flaws. Of these, the most serious threat that weakens investors' confidence from time to time is the behind-the-scene activities by syndicate of heavy-weight players such as wealthy individuals having nexus with the DSE or SEC (Note 2) management or the ruling or opposition political parties. These syndicates capitalize the myopic behavior of petty players. They pull stock prices up overnight by placing huge buy orders at a time - a phenomenon known as 'trigger buy'. There is evidence that most often the big players target stocks with poor fundamental background, some of which are hardly traded in the normal market condition (Note 3). The syndicate members trade these stocks among themselves for sometimes and places huge buy orders in order to make an impression in the market that there is no good or bad security as long as profits come overnight. This tempts the petty players to buy the poor-stocks, resulting inevitably in loss of their hard-earned liquidity. Even though the petty players are not always absolutely oblivious of the syndicate activities, and they are not always unsure of the status of the stocks they are buying, 
all of a paradox, they employ everything (time, money, greed) but a rational judgment. This behavior of petty-players is due partly to their myopia - the tendency of making profits overnight, and partly due to their counterpart - big-players - who put in place the deceptive idea that there is no good or bad security as long as profits come overnight. The primary objective of this paper is to formally reject such a deceptive idea. We argue that investors should not be fooled by the dramatic increase in the prices of poor-fundamental securities. They should not behave like dirt-thrower as investors in efficient markets might do. DSE is an inefficient market. Investors need to be selective in their choice of companies listed in DSE.

Our results support the idea that investors are better off risk-wise when they allocate funds to stocks belong to large business groups in the country such as Beximco, Basundhara, and Square. Our analyses reveal that investors' losses during the recent crash would be significantly smaller had they invested their money in portfolios of stocks with relatively sound fundamentals for example companies belong to large business groups or conglomerates. This renders a lesson for the investors in the market, especially who are myopic in nature, that stocks with good fundamentals are better not only as long term investments but also for gains in the short-run. Stocks with poor fundamentals may deceive to have high potential for gains in the short run - most often results from syndicated price appreciation - but actually that promise turns into a tragedy to the small and medium scale investors as the benefit of such price rise is almost exhaustively swallowed by the syndicate of a few big players. The recent episodes of boom and bust bear testimony of the fact.

The paper is organized as follows: Section 2 highlights the recent developments in the capital market of Bangladesh followed by a brief review of related studies. Section 3 describes the research methodology and data. Section 4 analyses and interprets results while Section 5 concludes the paper.

\section{Background}

\subsection{A Glimpse of Bangladesh Capital Market}

The financial system of Bangladesh is predominantly bank-based (Figure 1). Though stock markets grew slowly in terms of the volume of issued capital and number of companies listed in DSE (Figure 2), the overall size of stock markets (measured by the ratio of stock markets' capitalization to GDP) remained far below the size of banks (measured by the ratio of deposit money bank assets to GDP) during the last decade (Figure 1).

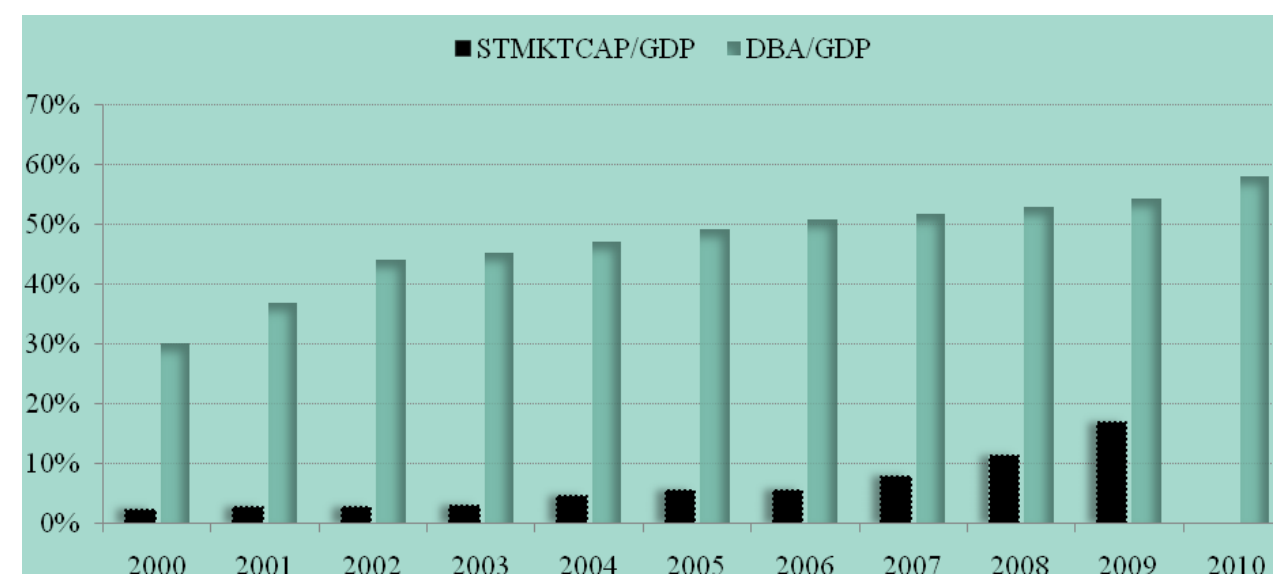

Figure 1. Banks vs stock markets

Note: The vertical axis measures the ratios namely DBA/GDP (Deposit money bank asset to GDP) and STMKTCAP/GDP (Stock Markets Capitalization to GDP).

Source of Data: Beck, and Demirgüç-Kunt (2009) and Bangladesh Bank (2012)

DSE is the principal organized securities exchange in Bangladesh. It is mainly a market for corporate stocks. Although other instruments such as corporate bonds and government securities are listed, they are rarely traded. As on 19 January 2012, number of listed securities was 501 comprising 235 shares, 8 corporate bonds and 221 treasury bonds - which all together were worth US\$30,074.71 million (DSE 2012). A second bourse named Chittagong Stock Exchange (CSE) listing 232 securities of 201 corporations also operates, but its role in the capital market of the country is trivial compared to DSE (GOB 2011). 


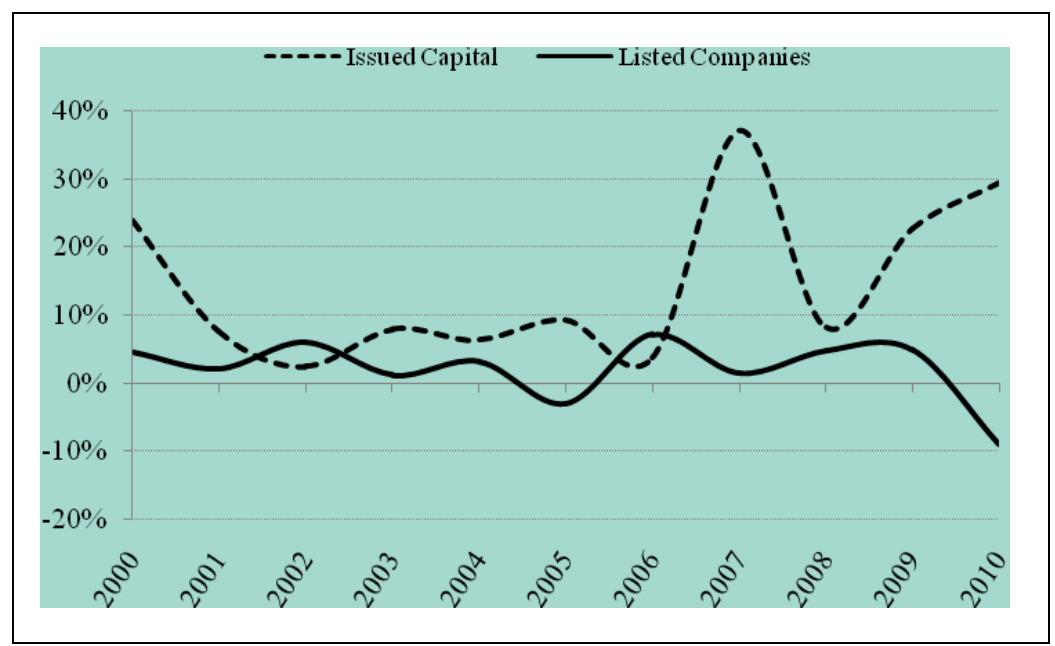

Figure 2. DSE growth during 2000-2010

Note: The vertical axis represents changes in the variables (issued capital and listed companies) over the previous year while the horizontal axis represents year.

Source of Data: Bangladesh Bank (2012)

Stock markets emerge as a major headache recently for the present government as hasty ups and downs in stock prices and resulting outburst of the loss-stricken petty-players have been a routine event in the market place (Note 4). Although booms and busts are common phenomena in any stock market, the origin and dynamics of these events differ between the stock markets of Bangladesh and developed counties. For example, the effects of 2008 global financial crisis (GFC) did not spill to DSE.
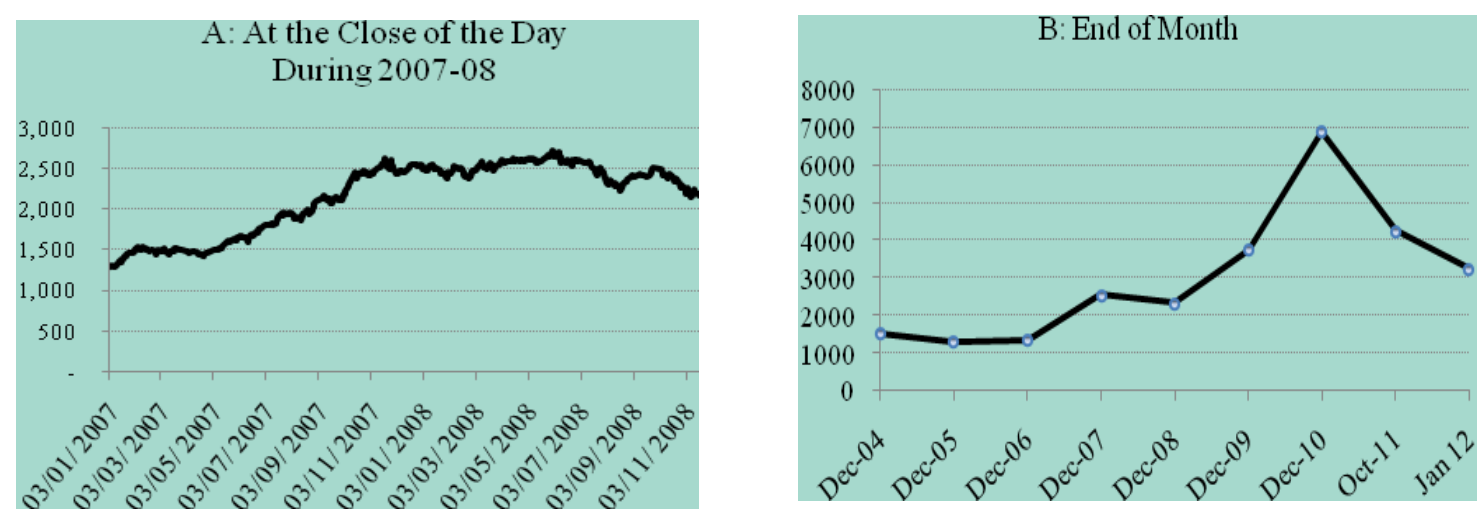

Figure 3. DSE all share price index

Note: DSE All Share Price Index at the close of a trading day (Panel A) and at the end of a month (Panel B).

Source of Data: DSE (2012).

In fact, the stock markets in Bangladesh were bullish on average during years 2007 and 2008 (Figure 3) by sharp contrast to the markets elsewhere e.g. the USA and Europe. This is primarily due to fact that the Bangladesh market is not integrated with global capital markets. Presence of foreign portfolio investors in the capital market is insignificant. Foreign portfolio investments could not account for even 0.20 percent of the country's GDP over the last decade (see Figure 4) despite a number of incentives for the foreign investors (Note 5). 


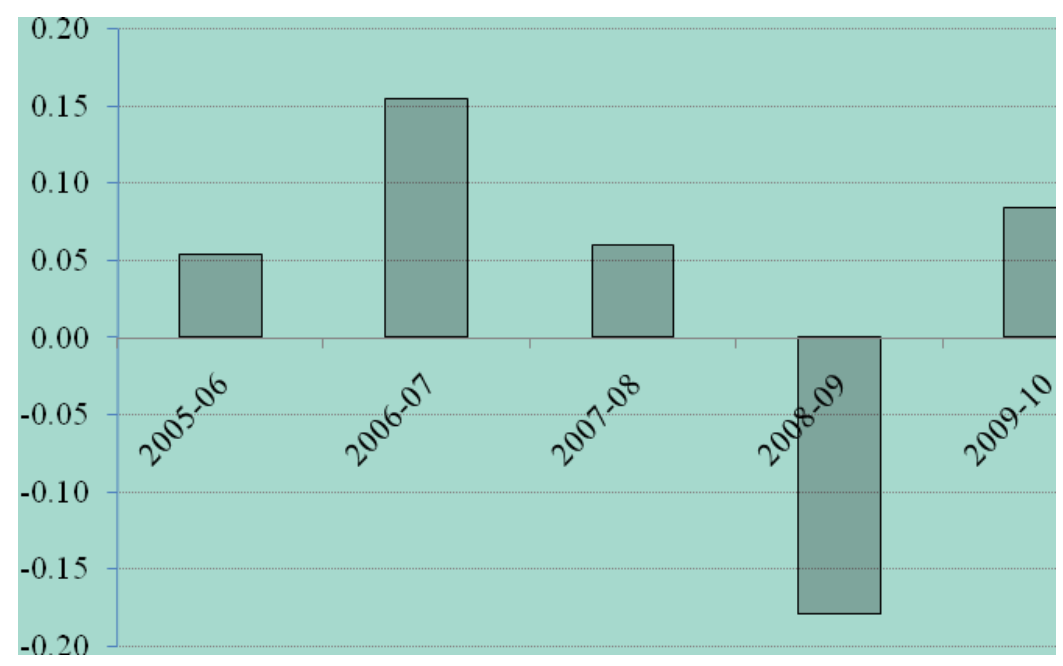

Figure 4. Foreign portfolio investment as \% of GDP

Note: Calculated from portfolio investment data and GDP data available at the SEC, Bangladesh and Bangladesh Bank websites respectively.

The stock markets of Bangladesh experienced episodes of bubbles and busts for the first time in 1996. The market survived that debacle and grew steadily through 2008. During 2009 through late 2010, the market started forming speculative bubbles again - grew sharply over the period 2009-10 then fell swiftly in January 2011. The market is still turbulent - experiencing chaotic movements every now and then. Many reasons pumped the market up. A primary one is the demand-supply mismatch. Whilst supply of fundamentally sound securities was not enough, demand was enormous due to massive inflow of liquidity from sources like garment exporters and non-resident Bangladeshis. According Chowdhury (2012), between 2006 and 2011 Bangladesh's booming garment industry fueled average economic growth of $6.3 \%$. The country's growth spurt was fueled by the garment industry, where some 2.5 million workers toiled for about US\$40 a month. Low costs helped Bangladesh become a hub for global apparel makers. In 1993, the value of Bangladesh's garment exports was under US\$2 billion. By 2011, garment exports had risen six folds to $\$ 17.9$ billion. These were paired with another fast-growing export from Bangladesh: Bangladeshis. Some 5 million Bangladeshis work abroad, and the $\$ 12$ billion they sent home in 2011 swelled Bangladesh's $\$ 100$ billion economy with cash. Coupled with the earnings from garment exports, that cash flooded into more than three dozen banks in the country. As inflation crept up and more banks entered the marketplace, the pressure to generate higher returns for depositors mounted. The central bank loosened restriction on banks - allowing them to invest a tenth of their total liabilities in the market. This, in turn, turned banks into stock-market speculators. As banks poured money into stocks, the market rocketed skyward. The rising spree got momentum by the influx of black money (Note 6) into the market. In 2010 , the DSE benchmark index climbed over $90 \%$. Such thrilling gains lured millions of petty players hungry for gains overnight. Retail brokerage accounts in Bangladesh jumped sevenfold from roughly half a million in 2007 to 3.5 million by 2010. Inevitably, almost the entire folk of these petty players were broke as big players suddenly exit the roller-coaster market in early 2011.

A serious menace in the stock market of Bangladesh is the syndicated speculation causing anarchy in the market from time to time. Speculative activities are a regular phenomenon in any stock market. Speculation keeps the market volatile and volatility to some extent necessary for liquidity of the market. However, speculative activities need to be closely monitored and be allowed only to the extent necessary to keep the market alive. Otherwise speculation provokes irrational behavior e.g. bidding the market up - in extreme cases - too high to be explained by any logic. These extreme cases, popularly known as speculative bubbles, take the worst form when speculation takes place by syndicates consisting of corporate insiders, exchange officials, business tycoons, bank managers and people having nexus with regulators or political parties. In such instances the market moves at the direction of the syndicate. The syndicate bids prices unusually high even of those securities which have been out of sight for years due to poor performance. The syndicate repeats the trick for sometimes so that the others - who do not belong to the syndicate, e.g. the petty player (small and medium scale investors) - are deceived and buy the already overvalued securities in the up market. Then all of a sudden, the syndicate triggers 
sales, resulting steep fall in prices overnight.

It is not that the petty players are completely unaware of the possible consequences of such market timing game or that they are ignorant of their unscrupulous competitors - the giant syndicate. Then why do not they quit the market? Understandably, to fulfill their greed even though they know that the greed has to be filled out of the leftover of the affluent players - if there is any at all. In general, the petty players are myopic - not willing to commit fund for a long term and expect returns overnight. They are risk lover-run after gains overnight regardless of the risk - buy risky overvalued securities and hope to sell them to some greater fool (Note 7). Unfortunately, at the end of the day the petty players lose the game, find themselves broke while big players (members of the syndicate) flee. The climax of the drama is always a disaster for the average investors. It is for this reason John Maynard Keynes likened stock market to casinos long ago (Keynes, cited in Singh 1993). The same remark about the stock market of Bangladesh was made recently by Rehman Sobhan - the country's eminent economist (DM 2011). Sobhan and many others held investors' greed responsible for the catastrophic incidents in the market. They blamed regulators for fueling the greed (Note 8).

Regulating the stock market has always been a challenge for Securities and Exchange Commission (SEC) - the country's capital market regulator (Note 9). The commission's credibility was questioned on a number of occasions. For instance, it was blamed for unwise approval of initial public offer (IPO) applications and ineffective control over unfair practices in the secondary market during the 90s when the country's stock market experienced the bubble-bust drama for the first time in the recent past. In early $90 \mathrm{~s}$, the government offered some incentives for ongoing entities and new entrepreneurs willing to raise fund by selling equity or debt instruments to the general public. Responses from entrepreneurs were too enormous to handle by the regulator. Many on-paper companies (those not yet in operation, have just a signboard on a piece of land) sneaked into the IPO market through the loopholes of either government policies or the commission's policy implementation or both. None of these companies yield anything for the shareholders - neither dividend nor capital gain - for long time. Even some of them fell in Z-basket- a category of DSE-listed companies which have failed to hold the current annual general meetings or have failed to declare any dividend or which are not in operation continuously for more than six months or whose accumulated loss after adjustment of revenue reserve, if any, is negative and exceeded its paid up capital. Oddly though, most of these issues were oversubscribed in the IPO market and traded for a higher than average market return on the first day of trading in the secondary market (Note 10). A textbook explanation of this excess return is the reward for the excess risk. IPOs are believed to be undervalued in general, hence reward higher returns. But the temporary under-price disappears in course of time. As more and more traders run after the under-valued issues for higher return, their prices soon reach the equilibrium and excess returns vanish. But this is a tale of efficient markets, and only partially true of DSE for the reasons mentioned in the previous paragraphs. A new approach was activated with a view to improving fairness and transparency in pricing and allocation of IPOs but the situation turned worse.

IPOs in Bangladesh used to be issued at a price proposed by the issue managers and approved by SEC. This approach (called fixed price method) proved faulty as there were strong allegations that the issue managers in collaboration with unscrupulous SEC personnel could manage to fix prices arbitrarily high. In fact, a number of IPOs were issued at premiums without strong justification. In 1999, SEC decided to replace the fixed price approach by book-building approach. This method is working well in big markets like India but proved ineffective in Bangladesh because of syndicated activities. An investigation report held syndicated malpractices in the IPO market largely responsible for the recent bubble and bust in the market (GOB 2011).

List of problems can be extended far beyond. But how can these defects be fixed? There is no magic cure to these market maladies. No doubt, regulators need to be proactive rather than spectator when syndicated price manipulation takes place. Appropriate and timely legal action would definitely ease investors' frustration to a large extent. Investors at the same time need to behave rationally. They should mind every step and must not be risk-blind. They need to apply a strategy that minimize risk. This paper is concerned with such a strategy. We hypothesize that because DSE is not an efficient market, investors should not pick shares randomly. Rather, they should be biased to shares with good fundamentals for example companies belong to big business conglomerates namely Beximco, Basundhara, Square and Apex etc because the risk (measured by VaR) of a bias portfolio is smaller than a random portfolio.

\subsection{Related Studies}

Studies on DSE so far are primarily concerned with market efficiency and volatility. To name a few of these are Chowdhury, Rahman and Akhter (2003), Sadique and Chowdhury (2002) and Hassan, Islam and Basher (2000). Among the recent ones are Khan (2009) and Salahuddin and Khoda (2009). In one way or another, these studies 
point to the fact that DSE is an inefficient market. Furthermore, there is a consensus among analysts and economists (e.g. GOB 2011, DM 2011) that DSE investors, including individuals and institutions, are by and large myopic. They expect return on their investment in a month or two if not overnight. This study founds on these ideas. However, like the studies mentioned above, this study does not test efficiency but tests an investment strategy that we believe to be useful in a troubled market like DSE.

\section{Methodology}

We seek answer to the question: are the investors better off in terms of minimizing risk if they construct portfolios comprising companies belong to large business groups (conglomerates) in Bangladesh like Beximco, Meghna or Square? Accordingly, two sets of five-asset equally weighted portfolios are constructed. We call them random and bias portfolios. The first set of portfolios consists of five randomly picked stocks from a sample of 180 companies actively traded in the market over the years 2008 and 2009. The second set of portfolios is biased to companies belong to large business groups. We intentionally keep at least two companies from large groups while the others are picked randomly from the same sample. Then VaR is estimated for 100 portfolios of each category - random and bias - at various dates during the period 2008-2010. We employ three approaches to VaR calculation namely historical, parametric and semi-parametric (Monte Carlo) VaR. In the Monte Carlo approach, we relax the normality assumption of risk factors (stock returns) and consider a mixture of non-normal distributions with excess kurtosis. Finally we apply statistical test to examine if there is any difference in risks between the two set of portfolios.

VaR is popular measure of market risk - the risk that arises from the adverse market movements in the prices of financial assets (Note 11). It refers to a portfolio's worst outcome that is likely to occur at a given confidence level over a particular time horizon. The reason $\mathrm{VaR}$ is so popular as a measure of risk is the fact that it interprets risk in a single dollar term. For example if a portfolio has a $99 \%$ one-day VaR of say $\$ 1000$, it means that the probability is only 1 percent that the loss would exceed $\$ 1000$ next day. Thus, VaR is a stochastic measure of future changes in the value of the asset. The future changes are predicted from the past changes. If the pattern of future changes is not identical to that of the past changes, VaR will be misleading. This may be the case in a historical VaR.

Under the historical approach, future returns are simulated from the past returns assuming that the distribution of changes in the future will remain the same as the distribution in the past. We use two techniques for historical simulation. One is a basic approach and the other is the bootstrap simulation. Under the basic approach, VaR of a portfolio is estimated from portfolio returns defined in (1) where $r_{p, t}$ is the return on an equally weighted portfolio of five companies $i=1, \ldots 5, P_{i, t}$ and $r_{i, t}$ are the $i^{\text {th }}$ company's price and return respectively at the close of day $t$.

$$
r_{p, t}=\frac{1}{5} \sum_{i=1}^{5} r_{i, t} \text { where } r_{i, t}=\frac{P_{i, t}-P_{i, t-1}}{P_{i, t-1}}
$$

We use 125 past observations of 1-day, and 120 observations of 10-day portfolio returns to calculate historical VaR at time $t$. Then VaR is estimated as the $1^{\text {st }}$ percentile, $5^{\text {th }}$ percentile and $10^{\text {th }}$ percentile from the smallest returns for $99 \%, 95 \%$ and $90 \%$ level of confidence respectively.

Bootstrap VaR is not much different from the basic historical VaR estimated above. The only reason risk managers consider the bootstrap technique is to attain greater degrees of freedom without imposing any assumption about the historical distribution. Under the bootstrap method, we pick any five observations of $r_{i}$ (one for each company in a portfolio) at a time from a sample of 125 observations (spanning a period of about 6 six months). Then return of the portfolio $r_{p}$ for this trail is calculated. We generate 1000 observations of 1-day return by repeating the process a thousand times. Because the bootstrap method is pretty time consuming, we consider only 99 percent 1 -day VaR which is again the smallest of all 1 percentile point of the 1000 simulated values of $r_{p}$.

If past changes in portfolio returns are assumed to follow normal probability distribution with zero mean and unit standard deviation where cumulative probability of a given a number $(z)$ can be defined as

$$
P\left(z_{t}\right)=\frac{1}{\sqrt{2 \pi}} \exp \left(-\frac{1}{2} z_{t}^{2}\right)
$$


then VaR at time $t$ can be located by integrating (2) over - $\infty$ to $\operatorname{VaR}_{t}^{1-\alpha}$ as under:

$$
P\left(z_{t} \leq \operatorname{VaR}_{t}^{1-\alpha}\right)=\int_{-\infty}^{V a R_{t}^{1-\alpha}} \frac{1}{\sqrt{2 \pi}} \exp \left(-\frac{1}{2} z_{t}^{2}\right)
$$

where $\alpha$ represents the confidence level. By this definition, if we want for example N-day VaR at a $99 \%$ confidence level, the calculation simplifies to (4) where $z$ (which in probability terminology called the inverse cumulative normal distribution) is -2.33 for an $\alpha$ of $99 \%$ and $\sigma$ is the standard deviation measuring volatility over $\mathrm{N}$ days of portfolio returns $r_{p}$ defined in (1).

$$
\begin{aligned}
& z=\frac{V a R_{t}^{1-\alpha}-\mu}{\sigma}=-2.33 \\
& \operatorname{VaR}_{t}^{1-\alpha}=-2.33 \sigma+\mu
\end{aligned}
$$

VaR in (4) is called parametric because it needs only two parameters of the distribution of portfolio returns $\left(\gamma_{p}\right)$ namely mean $\mu$ and volatility $\sigma$. Mean is zero by the assumption of standard normal distribution. We use a conditional measure of volatility called exponentially weighted moving average (EWMA) volatility defined in formula (5) where $\sigma_{\mathrm{p}, \mathrm{t}}$ is the EWMA standard deviation of portfolio $p$ per step of time $t$ e.g. 1-day, 5-day, etc. over 100 days, $\lambda$ decay factor and $\gamma_{\mathrm{i}, 100-\mathrm{n}}$ and $\gamma_{\mathrm{j}, 100-\mathrm{n}}$ are the observations of daily returns on company $i$ and $j$.

$$
\sigma_{p, t}=\sqrt{\left.\sum_{i=1}^{5} w_{i}^{2} \sum_{n=1}^{100}(1-\lambda) \lambda^{100-n}\left(r_{i, 100-n}\right)^{2}+\sum_{\substack{i, j=1 \\ \forall i \neq j}}^{5} w_{i} w_{j} \sum_{n=1}^{100}(1-\lambda) \lambda^{100-n}\left(r_{i, 100-n} \times r_{j, 100-n}\right)\right]}
$$

The EWMA approach to measuring volatility assumes that recent observation gives better information about the market condition. Accordingly, it applies the maximum weight to the most recent volatilities. Following the industry convention for example Riskmatrix ${ }^{\circ}$, we choose a decay factor of 0.94 . Thus the $100^{\text {th }}$ observation of a series of portfolio returns, which represents the present time, takes the maximum weight of $(1-\lambda) \lambda^{100-100}=1-.94=0.6$. The weight declines exponentially as we go backward.

In Monte-Carlo approach, we simulate correlated vectors of portfolio returns using Cholesky decomposition. The Cholesky decomposition partitions the covariance matrix of portfolio returns satisfying (6).

$$
\left[\begin{array}{ccccc}
\sigma_{1,1} & \rho_{1,2} \sigma_{1} \sigma_{2} & \cdot & \cdot & \rho_{1,5} \sigma_{1} \sigma_{5} \\
\rho_{2,1} \sigma_{2} \sigma_{1} & \sigma_{2,2} & \cdot & \cdot & \cdot \\
\cdot & \cdot & \sigma_{3,3} & \cdot & \cdot \\
\cdot & \cdot & \cdot & \sigma_{4,4} & \cdot \\
\rho_{5,1} \sigma_{5} \sigma_{1} & \cdot & \cdot & \cdot & \sigma_{5,5}
\end{array}\right]=\left[\begin{array}{ccccc}
C_{1,1} & 0 & 0 & 0 & 0 \\
C_{2,1} & C_{2,2} & 0 & 0 & 0 \\
C_{3,1} & C_{3,2} & C_{3,3} & 0 & 0 \\
C_{4,1} & C_{4,2} & C_{4,3} & C_{4,4} & 0 \\
C_{5,1} & C_{5,2} & C_{5,3} & C_{5,4} & C_{5,5}
\end{array}\right] \times\left[\begin{array}{ccccc}
C_{1,1} & C_{1,2} & C_{1,3} & C_{1,4} & C_{1,5} \\
0 & C_{2,2} & C_{2,3} & C_{2,4} & C_{2,5} \\
0 & 0 & C_{3,3} & C_{3,4} & C_{3,5} \\
0 & 0 & 0 & C_{4,4} & C_{4,5} \\
0 & 0 & 0 & 0 & C_{5,5}
\end{array}\right]
$$

$\sigma^{\prime} s$ in left-hand side matrix are the EMMA standard deviations of individual companies and $\rho^{\prime} s$ are the coefficient of correlation between returns of each pair of companies in a portfolio. Product of the two matrixes on the right hand side of (6) is called Cholesky matrix. Elements of Cholesky can be expressed in terms of the corresponding elements in the covariance matrix e.g. $\left(C_{1,1}\right)^{2}=\sigma_{1,1}$ or $\left(C_{1,1}\right)^{2}=\sigma_{1}$ (because $\sigma_{1,1}=\sigma_{1}^{2}=$ Variance of any company 1 in a portfolio), $\mathrm{C}_{1,2}=\rho_{1,2} \sigma_{2}, C_{5,5}=\sqrt{\sigma_{5}^{2}-C_{1,5}^{2}-C_{2,5}^{2}-C_{3,5}^{2}-C_{4,5}^{2}}$. Given these decomposed variance and covariance of observed returns of individual companies, we can simulate new vectors of returns $(X)$ defined in (7) where $Z$ is a random number with zero mean and unit standard deviation. 


$$
\left[\begin{array}{l}
X_{1} \\
X_{2} \\
X_{3} \\
X_{4} \\
X_{5}
\end{array}\right]=\left[\begin{array}{ccccc}
C_{1,1} & 0 & 0 & 0 & 0 \\
C_{2,1} & C_{2,2} & 0 & 0 & 0 \\
C_{3,1} & C_{3,2} & C_{3,3} & 0 & 0 \\
C_{4,1} & C_{4,2} & C_{4,3} & C_{4,4} & 0 \\
C_{5,1} & C_{5,2} & C_{5,3} & C_{5,4} & C_{5,5}
\end{array}\right] \times\left[\begin{array}{c}
Z_{1} \\
Z_{2} \\
Z_{3} \\
Z_{4} \\
Z_{5}
\end{array}\right] \text { where } Z \sim N(0,1)
$$

However, $X$ 's in (7) are standard normal. But observed returns exhibit excess kurtosis (more than 3). VaR estimates will be misleading if we use $X$ 's given by (7). We therefore need to simulate $X$ 's with kurtosis in excess of 3. To do that, we apply an approach suggested by Delianedis, Lagnado and Tikhonov (2000) where non-normal vectors are simulated from a mixture of normal distributions but the simulated vectors have the same covariance matrix as the covariance matrix of the observed vectors expressed by the right hand side matrix in (6). The method is briefly described below.

Let $Z_{A}$ and $Z_{B}$ be zero-mean normally distributed random variables with variances $\sigma_{\mathrm{A}}{ }^{2}$ and $\sigma_{\mathrm{B}}{ }^{2}$ respectively. We want to construct a new random variable $X$ by sampling from the distribution of $Z_{A}$ with probability $p$ and from the distribution of $Z_{B}$ with probability $1-p$. We do this by introducing a uniformly distributed random variable $U$ assuming values in the interval $[0,1]$ that is independent of $Z_{A}$ and $Z_{\boldsymbol{B}}$. Thus, the random variable $X$ is given by

$$
X=1_{\{U \leq p\}} Z_{A}+1_{\{U>p\}} Z_{B}
$$

where $1_{\{.\}}$is the indicator function assuming the value 1 or 0 depending upon whether the condition within the braces is true or false, respectively. The moments of $X$ are given by

$$
\begin{aligned}
& E(X)=0 \\
& E\left(X^{2}\right)=p \sigma_{A}^{2}+(1-p) \sigma_{B}^{2} \\
& E\left(X^{3}\right)=0 \\
& E\left(X^{4}\right)=3 p \sigma_{A}^{4}+3(1-p) \sigma_{B}^{4}
\end{aligned}
$$

When $\sigma_{\mathrm{A}} \neq \sigma_{\mathrm{B}}$ and $0<\mathrm{p}<1$, we find Kurtosis $K_{X}=\frac{E\left(X^{4}\right)}{E\left(X^{2}\right)^{2}}>3$. To facilitate Monte Carlo simulation with a heavy-tailed distribution, we select values for the parameters $p, \sigma_{\mathrm{A}}$ and $\sigma_{\mathrm{B}}$ such that the variance of $X$ is 1 and the coefficient of kurtosis is a specified value $k$. This requires solving the equations (10) and (11) simultaneously.

$$
\begin{gathered}
p \sigma_{A}^{2}+(1-p) \sigma_{B}^{2}=1 \\
3 p \sigma_{A}^{4}+3(1-p) \sigma_{B}^{4}=k
\end{gathered}
$$

Solving for $\sigma_{\mathrm{i}}$ and $\sigma_{\mathrm{j}}$ in terms of $p$ we find

$$
\begin{aligned}
\sigma_{A}^{2} & =1-\sqrt{1-\frac{1-k(1-p) / 3}{p}} \\
\sigma_{B}^{2} & =\frac{1-p \sigma_{A}^{2}}{1-p}
\end{aligned}
$$

To ensure that $\sigma_{\mathrm{A}}^{2}>0$ and $\sigma_{\mathrm{B}}^{2}>0, p$ needs to be restricted within $1-3 / \mathrm{k}<\mathrm{p}<1$. To select a specific $p$, the ratio of standard deviations, $\sigma_{\mathrm{A}} / \sigma_{\mathrm{B}}$ is minimized. This results in the two mixture standard deviations being as close to one as possible (note that ${\sigma_{\mathrm{B}}}^{2} \geq 1 \geq \sigma_{\mathrm{A}}{ }^{2}$ by construction). The resulting $p$ is given by

$$
p=\frac{\left(\sqrt{\frac{k}{3}-1}+\sqrt{\frac{k}{3}}\right)^{2}}{1+\left(\sqrt{\frac{k}{3}-1}+\sqrt{\frac{k}{3}}\right)^{2}}
$$

For multivariate applications, we need to extend the above procedure to construct a random vector with a desired correlation structure and where each component has a specified kurtosis. Suppose that $Z$ is a random vector with 
a multivariate normal distribution, such that each component has mean 0 and variance 1 and with correlation matrix

$$
E\left(Z Z^{T}\right)=R
$$

where $R$ is the correlation matrix of observed returns. Let $k$ be the vector of specified kurtosis coefficients. First we obtain a single probability $p$ and mixture standard deviations $\sigma_{A i}$ and $\sigma_{B i}$ for $i=1,2, \ldots, N$ such that

$$
\begin{aligned}
& p \sigma_{A i}^{2}+(1-p) \sigma_{B i}^{2}=1 \\
& 3 p \sigma_{A i}^{4}+3(1-p) \sigma_{B i}^{4}=k_{i}
\end{aligned}
$$

Now we define diagonal matrixes as under:

$$
\begin{aligned}
& \Sigma_{A}=\operatorname{diag}\left(\sigma_{A 1}, \sigma_{A 2} \ldots . \sigma_{A N}\right) \\
& \Sigma_{B}=\operatorname{diag}\left(\sigma_{B 1}, \sigma_{B 2} \ldots . . \sigma_{B N}\right)
\end{aligned}
$$

Then, we define the random vactor

$$
X=1_{\{U \leq p\}} \Sigma_{A} Z+1_{\{U>p\}} \Sigma_{B} Z
$$

where $Z \square N(0,1), U$ is an independent uniformly distributed random variable assuming values in the interval [0,1]. By construction, the marginal distributions of the components of $X$ will have the desired statistical properties, e.g. mean zero, variance 1 , skewness 0 and kurtosis $k_{\mathrm{i}}$. Also, $X$ has the following correlation matrix:

$$
E\left(X X^{T}\right)=\left[p \Sigma_{A} R \Sigma_{A}+(1-p) \Sigma_{B} R \Sigma_{B}\right]
$$

Finally VaR is estimated as the $1^{\text {st }}$ percentile, $5^{\text {th }}$ percentile and $10^{\text {th }}$ percentile of the smallest $X$ for $99 \%, 95 \%$ and $90 \%$ level of confidence respectively.

We consider 100 portfolios of each category. Hence the three types of VaR are calculated for 100 bias and 100 random portfolios. Then the difference in VaR of the bias and the random portfolios is tested for statistical significance. We use a t-test for the null hypothesis that the means of the difference between VaR for the bias and random portfolios are equal. Furthermore, we estimate probability of the extent of differences by a non-parametric measure called kernel density estimate.

\section{Results}

Table 1 presents the results of our analyses. The table reports the means of the $99 \%$ historical, parametric, Monte Carlo and bootstrap VaR of 100 random (R) and 100 bias (B) portfolios for 1 and 10 day horizons. R-B in the table stands for the difference in the mean of VaR of these portfolios. To put it in plain, our results reveal that on average, the total risk of random portfolio is greater than that of a bias portfolio. The differences are clearly exhibited in Figures 5 ( $a$ and $b$ ) and 6. Figure 5 depicts the Kernel density of (R-B). We can observe that by and large the density of the differences are skewed to the right of zero. We can see in Figure 6 that the frequency of positive difference is greater than negative counts of R minus B. Furthermore, we find statistically significant positive difference between the mean $\mathrm{VaR}$ of the random and bias portfolios and the hypothesis of equal mean is rejected for all but the 99\% 10 day historical VaR (Table 1). A probable explanation for this exception may be the fact that historical approach to VaR does not consider the changing dynamics of volatility whereas the parametric and semi-parametric (Monte Carlo) does by applying more weights to recent observations than the distant ones. Thus, this exception does not enforce a compromise to what we find in theoretically better approaches.

Overall, our result reveals that investors in DSE are better off risk-wise when they allocate funds to stocks belong to large business groups such as Beximco, Basundhara, and Square. A possible explanation is that companies belong to conglomerates are fundamentally better than others in general. This renders a lesson for investors in the market, especially who are myopic in nature, that stocks with good fundamentals are better not only as long term investments but also for gains in the short-run. DSE is an inefficient stock market. Investors should not behave like dirt-throwers when pouring money in shares traded in this market. 
Table 1. Difference in means of the random and bias portfolios

\begin{tabular}{|c|c|c|c|c|c|c|}
\hline & Portfolio & $\begin{array}{l}\text { Mean as \% } \\
\text { of } \\
\text { Investment }\end{array}$ & $\begin{array}{c}\text { Standard } \\
\text { Deviation as \% } \\
\text { of Investment }\end{array}$ & $\begin{array}{l}\text { R-B Count } \\
\text { Positive } \\
(\%)\end{array}$ & $\begin{array}{l}\text { Hypothesis: Difference of } \\
\text { Mean }=0 \text { at } 5 \% \text { Level of } \\
\text { Significance }\end{array}$ & $\begin{array}{l}\text { t-Stat for } \\
\mathrm{H}_{0}: \text { Equal } \\
\text { Mean }\end{array}$ \\
\hline \multirow[t]{3}{*}{ 99\% 1-Day His VaR } & Random (R) & 6.14 & 1.84 & & & \\
\hline & Bias (B) & 5.41 & 1.61 & & & \\
\hline & R-B & 0.73 & 2.50 & 62 & Rejected & 2.98 \\
\hline \multirow[t]{3}{*}{ 99\% 10-Day His VaR } & Random & 12.45 & 2.81 & & & \\
\hline & Bias & 11.88 & 3.67 & & & \\
\hline & $\mathrm{R}-\mathrm{B}$ & 0.57 & 4.67 & 58 & Could not be rejected & 1.86 \\
\hline \multirow[t]{3}{*}{ 99\% 1-Day Para VaR } & Random & 5.05 & 1.17 & & & \\
\hline & Bias & 4.49 & 1.00 & & & \\
\hline & $\mathrm{R}-\mathrm{B}$ & 0.56 & 1.55 & 66 & Rejected & 3.65 \\
\hline \multirow[t]{3}{*}{ 99\% 10-Day Para VaR } & Random & 16.99 & 4.71 & & & \\
\hline & Bias & 14.49 & 4.63 & & & \\
\hline & $\mathrm{R}-\mathrm{B}$ & 2.50 & 6.74 & 68 & Rejected & 3.78 \\
\hline \multirow[t]{3}{*}{ 99\% 1-Day MC VaR } & Random & 5.45 & 1.37 & & & \\
\hline & Bias & 4.97 & 1.17 & & & \\
\hline & $\mathrm{R}-\mathrm{B}$ & 0.48 & 1.86 & 60 & Rejected & 2.66 \\
\hline \multirow[t]{3}{*}{ 99\% 10-Day MC VaR } & Random & 18.65 & 6.02 & & & \\
\hline & Bias & 14.83 & 4.49 & & & \\
\hline & $\mathrm{R}-\mathrm{B}$ & 3.82 & 7.73 & 72 & Rejected & 5.08 \\
\hline \multirow[t]{3}{*}{ 99\% 1-Day Boot VaR } & Random & 4.95 & 1.44 & & & \\
\hline & Bias & 4.59 & 1.26 & & & \\
\hline & $\mathrm{R}-\mathrm{B}$ & 0.36 & 1.89 & 57 & Rejected & 2.68 \\
\hline
\end{tabular}
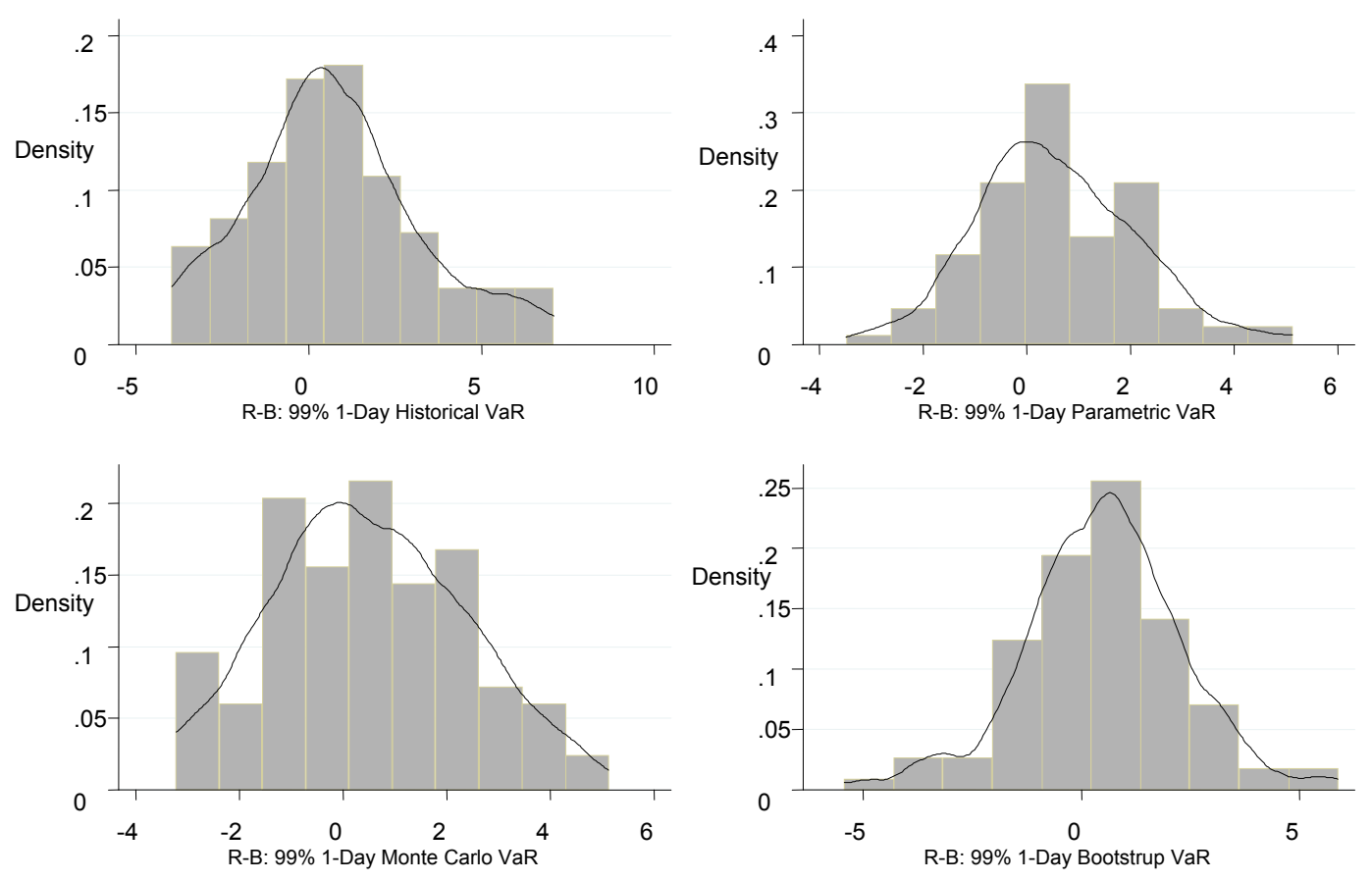

Figure 5. Kernel density of the differences in VaR 


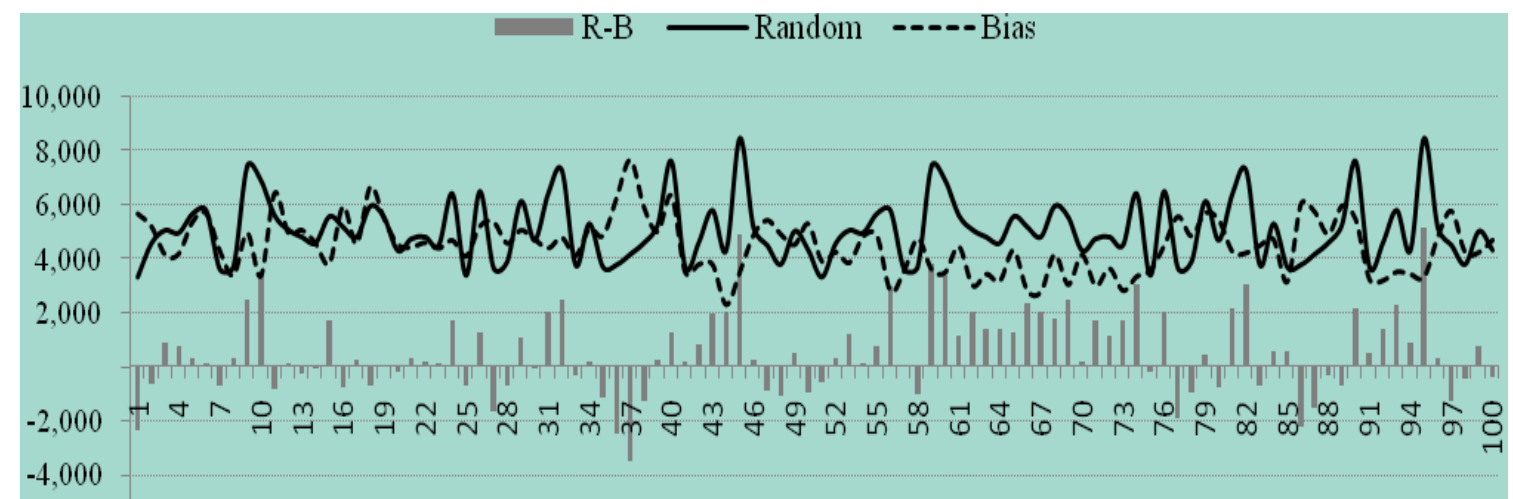

Figure 6a. VaR of random and the bias portfolios and their difference (R-B) 99\% 1-day parametric VaR

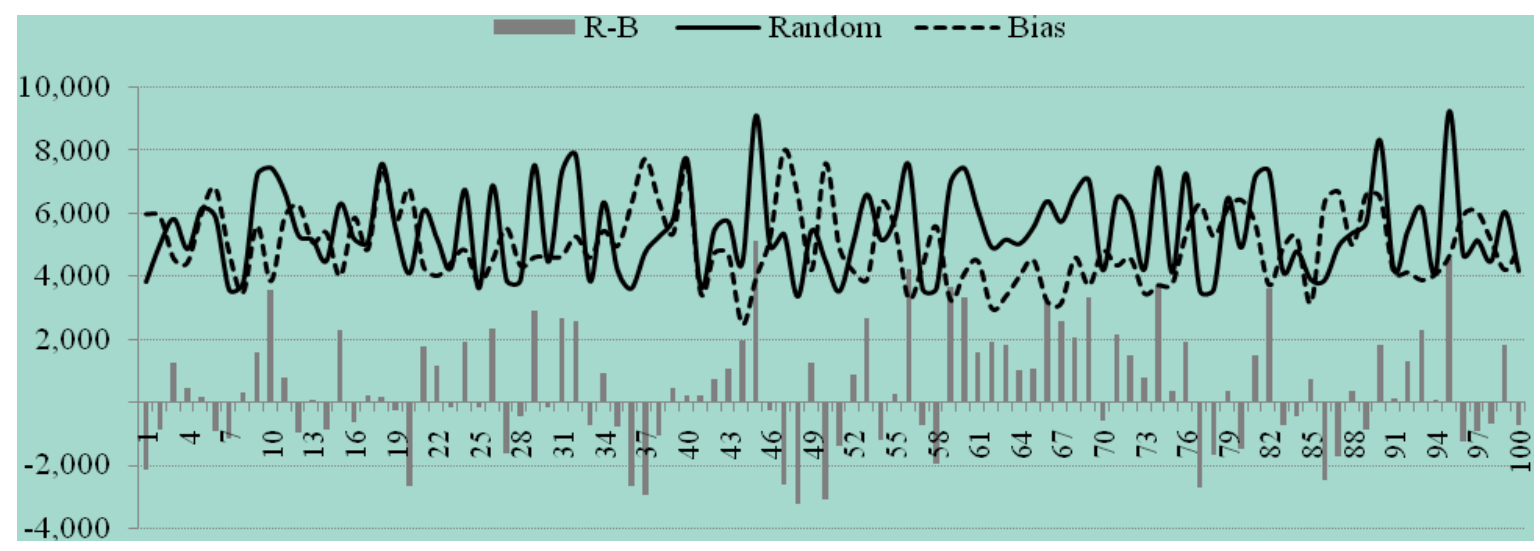

Figure $6 \mathrm{~b}$. VaR of random and the bias portfolios and their difference (R-B) 99\% 1-day monte-carlo VaR Note: The vertical axis measures VaR in local currency, Taka. The horizontal axis represents the portfolios. The size of each portfolio is Taka 100,000 comprising five stocks listed on DSE. Thus a 99\% 1-day VaR of say Taka 8000 means there is one percent probability of losing 8000 tomorrow if 100,000 is invested today (or $99 \%$ confident that the loss will not exceed Taka 8000). Bars in the figure are the differences between the Radom and Bias portfolios constructed at the same point of time.

\section{Conclusion}

This paper investigates whether investors in Dhaka Stock Exchange (DSE) -the principal bourse of Bangladesh can minimize risk by investing in portfolios comprising companies belong to large business groups (conglomerates) in the country like Beximco, Basundhara, or Square. Accordingly, two sets of five-asset equally weighted portfolios namely random and bias are constructed. The first set of portfolios consists of five randomly picked stocks from a sample of 180 companies actively traded in the market over the period January 2008 to August 2009. The second set of portfolios is biased to companies belong to large business groups. We intentionally keep at least two companies from large groups while the others are picked randomly from the same sample. Value at risk (VaR), a popular measure for market risk, is estimated for 100 portfolios of each categoryrandom and bias. Then the difference in VaR of the bias and the random portfolios is tested for statistical significance. Furthermore, we estimate probability of the extent of differences by a non-parametric measure called kernel density estimate. We employ three approaches to VaR calculation namely historical simulation, parametric and semi-parametric (Monte Carlo) method. For historical VaR we apply a basic simulation and a bootstrap method. For the parametric VaR, we employ an exponentially weighted moving average to estimate volatility. In the Monte Carlo approach, we use Cholesky decomposition to simulate multivariate risk factors. Because the DSE-listed stock returns have excess kurtosis, we employ a stochastic simulation technique that generates correlated risk factors with excess kurtosis from a mixture of normal distributions. Our result reveals that investors are better off risk-wise when they allocate funds to stocks belong to large business groups such as 
Beximco, Basundhara, and Square. A possible explanation is that companies belong to conglomerates are fundamentally better than others in general. This renders a lesson for investors in the market, especially who are myopic in nature, that stocks with good fundamentals are better not only as long term investments but also for gains in the short-run. DSE is an inefficient stock market. Investors should not behave like dirt-throwers when pouring money in shares traded in this market. Stocks with poor fundamentals may deceive to have high potential for gains in the short run - most often results from syndicated price appreciation. But that promise turns into a disaster for the small and medium scale investors as the benefit of such price rise is almost exhaustively swallowed by the syndicate of a few big players. The recent episodes of boom and bust bear testimony of the fact To revive the market into an effective mechanism of fund allocation, confidence of general investors must be regained. Investors, who want to stay in the market even after the painful losses, need to behave rationally in future investment attempts rather than look for a short-cut way to be wealthy overnight. DSE should have a mechanism in place to watch trading patterns of poor fundamental-shares and if necessary should stop trades temporarily for investigation especially when prices of low-profile shares increase continuously for a number of days.

\section{Acknowledgement}

We gratefully thank Mr. Abed Abdullah of the Independent University, Dhaka Bangladesh for assistance in data collection.

\section{References}

Akhter, S., \& Chowdhury, S. H. (1996). Price Behavior of common stock new issues: Evidence from and Emerging Equity Market. Journal of Business Administration, 22(3\&4), 35-73.

Alexander, C. (2008). Market risk analysis. John Wiley and Sons, Ltd.

Bangladesh Bank. (2012). Monthly Economic Trends, database. Retrieved from http://www.bangladesh-bank.org/openpdf.php

Beck, T., \& Demirgüç-Kunt, A. (2009). Financial institutions and markets across countries and over time: Data and analysis. World Bank Policy Research Working Paper No. 4943, May. http://dx.doi.org/10.1596/1813-9450-5072

Chowdhury, N. (2012). The rise and fall of one of the world's worst-performing stock markets' Time World. Retrieved from http://www.time.com/time/world/article/0,8599,2105845,00.html

Chowdhury, S. H., Rahman, A., \& Akhter, S. (2003). Cross-section of expected returns: the case of Dhaka Stock Exchange (DSE). The South Asian Journal of Management, 10(2), 7-12.

Delianedis, G., Lagnado, R., \& Tikhonov, S. (2000). Monte Carlo simulation of non-normal processes. MKIRISK Discussion Paper.

Dhaka Mirror (DM). (2011). Stock crash may hurt economy. Retrieved from http://www.dhakamirror.com/other-headlines/stock-crash-may-hurt-economy

Dhaka Stock Exchange (DSE). (2012). Market Statistics. Retrieved from http://main.dsebd.org/mst.txt

Government of Bangladesh (GOB). (2011). Report of the investigation of Stock markets. Dhaka.

Hassan, K., Islam, A., \& Basher, S. A. (2000). Market efficiency, time-varying volatility and equity returns in Bangladesh stock market. Working Paper, Department of Economics and Finance, University of New Orleans.

Jorion, P. (2007). Value at risk: The new benchmark for managing financial risk (3rd ed.). McGraw Hill.

Khan, S. (2009). Determinants of Share Price Movements in Bangladesh: Dividends and Retained Earnings. MSc thesis, Blekinge Institute of Technology.

Kindleberger C. P., \& Aliber, R. (2005). Manias, Panics, and Crashes: A History of Financial Crises (5th ed.). Wiley, 2005. http://dx.doi.org/10.1057/9780230628045

Sadique, S., \& Chowdhury S. H. (2002). Serial dependence in the DSE returns: An empirical Study. Journal of Bangladesh Studies, 4(1), 47-57.

Sala-Uddin, G., \& Khoda A. K. (2009). An empirical examination of random walk hypothesis for Dhaka Stock 
Exchange: Evidence from pharmaceutical sector of Bangladesh. International Research Journal of Finance and Economics, 33, 87-100.

Singh, A. (1993). The stock market and economic development: Should developing countries encourage stock markets? UNCTAD Review, 4, 1-28.

\section{Notes}

Note 1. See comments by the Center for Policy Dialogue (CDP ) - the country's leading policy think-tank at http://www.dhakamirror.com/other-headlines/stock-crash-may-hurt-economy, and a report (Chowdhury 2012)by an international news magazine at http:/www.time.com/time/world/article/0,8599,2105845,00.html

Note 2. Securities and Exchange Commission (SEC) is the country's stock markets regulator.

Note 3. See GOB (2011).

Note 4. For a recent media report visit http://www.time.com/time/world/article/0,8599,2105845,00.html

Note 5. For example no limitation pertaining to foreign equity participation, i.e. 100 percent foreign equity is allowed, full repatriation profits and dividend, and tax holiday etc. For more details, visit http://www.bangladesh-bank.org/investfacility/invesfac.php

Note 6. Black money is defined as accumulated income not declared to the tax authority. Tax evasion is widespread in Bangladesh. Undeclared income could account for up to $80 \%$ gross domestic product - some US $\$ 110$ billion, according to an Agence France-Presse (AFP) report citing a study by the Ministry of Finance, Bangladesh (see Online Asia Times dated July 7, 2011 at www.asiatimes.com). The country's 2009-10 budget allowed black money to be whitened by a token 10 percent tax on condition that the money invest in any of the 62 designated sectors including the stock market.

Note 7. The phrase borrowed from Kindleberger and Aliber (2005).

Note 8. Dhaka Mirror, $14 \quad$ February 2011 available at http://www.dhakamirror.com/other-headlines/stock-crash-may-hurt-economy/

Note 9. The Securities and Exchange Commission (SEC) Bangladesh was established in June, 1993 under the Securities and Exchange Commission Act, 1993. The Commission consists of five members appointed by the government.

Note 10. See Akhter and Chowdhury (1996) for a survey of IPOs in Bangladesh during 1992-1995.

Note 11. See Jorion (2007) and Alexander (2008) for comprehensive description of VaR. 